\title{
Addressing Mental Health in Elite Athletes as a Vehicle for Early Detection and Intervention in the General Community
}

Courtney C. Walton PhD ${ }^{\mathrm{a}^{*}}$, Rosemary Purcell PhD ${ }^{\text {b, c, d }}$, Simon Rice PhD b, c, d

${ }^{\text {a }}$ School of Psychology, The University of Queensland, Brisbane, Queensland, Australia

${ }^{\mathrm{b}}$ Orygen, The National Centre of Excellence in Youth Mental Health, 35 Poplar Road,

Parkville, Melbourne, VIC 3052, Australia

${ }^{\mathrm{c}}$ Centre for Youth Mental Health, The University of Melbourne, Melbourne, VIC, Australia

${ }^{d}$ Orygen Youth Health Clinical Program, Melbourne, VIC, Australia

\section{Running Title: Mental Health in Elite Athletes}

\section{* Correspondence should be addressed to Dr Courtney C. Walton.}

E-mail: c.walton@uq.net.au. Address: School of Psychology, The University of

Queensland, Brisbane, QLD, Australia

\section{Word Count: 1,171}

This is the author manuscript accepted for publication and has undergone full peer review but has not been through the copyediting, typesetting, pagination and proofreading process, which may lead to differences between this version and the Version of Record. Please cite this article as doi: 10.1111/eip.12857

This article is protected by copyright. All rights reserved. 


\begin{abstract}
Recent scientific literature in addition to increased media attention has highlighted the important role of mental health in elite athletes. Often defined by terms such as 'mental toughness', athletes are now becoming more open to discussing the role of anxiety, depression and other psychologically distressing processes that are intertwined with their time both during and after elite sport. In line with this, recent international position statements regarding the mental health of athletes have been released. The current New Hypothesis article follows on from these statements and proposes that further work must be done to better understand this aspect of elite sport in addition to developing sport-specific interventions for athletes, their families, and support staff. Further, we propose that by better understanding and treating the mental health of elite athletes a follow-on effect may occur, whereby help-seeking in the general community will increase. In particular, young adults who were previously hesitant to seek help may take strength from this shift, maximizing the success of early intervention occurring.
\end{abstract}

Key Words: Early Intervention; Elite Athletes; Mental Health; Youth Sport; Adolescents 
When picturing a vulnerable group of individuals who are disposed to dealing with unrecognized and poorly treated mental health problems, it is unlikely that elite athletes immediately come to mind. Peak physical condition among athletes can obscure their mental health needs. Many elite athletes who have achieved sporting success have publicly reported dealing with a mental health disorder, with cases of suicide in current and retired athletes known (Baum, 2013). Given this, the mental health and well-being of elite athletes has increasingly come to public, academic, and clinical attention, and here we highlight that this discourse may have an additional contribution to early intervention in the general community.

Currently, there is limited research regarding the prevalence and nature of mental health concerns in elite athletes, with a lack of targeted interventions available. What we do know is that athletes performing within elite settings report symptoms of clinical and subthreshold disorders at similar, if not slightly higher rates to healthy adults. These symptoms are hypothesised to relate to a range of competitive, organizational and personal stressors that can occur within the context of sport; such as heightened stress and pressure to perform, injuries, time away from support networks through exhausting travel schedules, public scrutiny and post-career transition (especially when non-voluntary) to a non-athletic identity (Gorczynski, Coyle, \& Gibson, 2017; Gouttebarge, Frings-Dresen, \& Sluiter, 2015; Gulliver, Griffiths, Mackinnon, Batterham, \& Stanimirovic, 2015; Henriksen et al., 2019; Hughes \& Leavey, 2012; Rice et al., 2016). 
The careers of elite athletes typically peak at similar age ranges to the onset of mental health disorders (Kessler et al., 2007), and youth-specific early intervention approaches are indicated (Rice et al., 2016). International position statements from key governing bodies have recently been published (Henriksen et al., 2019; Moesch et al., 2018; Schinke, Stambulova, Si, \& Moore, 2017) and this work represents a crucial step forward for the facilitation of mental health services for athletes. Indeed, in Australia, a recent government strategic plan has specifically highlighted improved mental health as a key outcome in both athletes, and the general public, as a result of sports participation and national success (Sport Australia, 2018). However, while the intent to tackle the problem is growing, addressing mental health in elite sport is complex. A number of roadblocks remain in terms of further progression: (a) stigma in coaching about the need for a mental health focus rather than performance-based approaches; (b) athletes being wary of teammate, coaching staff or opposition perceptions of their need for mental support in the culture of 'mental toughness' (Bauman, 2016); and (c) difficulties undertaking research with elite populations due to confidentiality, time and travel commitments, and funding. Highlighting some of these challenges, there is an absence of RCTs in the field of elite sports mental health intervention (Rice et al., 2018; Rice et al., 2016).

In addressing the current research gap, a promising recent RCT of The Optimum Performance Program in Sports (TOPSS) intervention (Donohue et al., 2018) recruited 74 collegiate athletes in the US, 59 of which reported a previous or current mental health disorder. Rather than focusing on the reduction of psychopathology, TOPSS employed an 
'optimisation' approach, emphasising the role that increased general well-being can have on sporting performance. The program reduced an array of mental health-based factors, and improvements were maintained over eight months, with the intervention particularly effective for those with more pronounced mental health problems. Of note, engagement rates with the intervention were substantially higher than with general counselling sessions on campus. While this study requires replication, the results support the benefits of specifically tailoring mental health intervention approaches to athlete populations.

We are at a critical timepoint for change within the sporting landscape, given the increasing awareness of mental health and well-being concerns within professional and elite athletes, and public statements to these effects. However, recent evidence suggests sporting organisations are not doing enough to promote mental health publicly (Liddle, Deane, \& Vella, 2017), and younger athletes may continue to observe stoic traits being glorified by those in sport, potentially minimising their confidence to seek help. Indeed, young athletes must be considered a key population for early detection and intervention as they are known to experience high rates of mental health problems (Hill, MacNamara, \& Collins, 2015; Hill, MacNamara, Collins, \& Rodgers, 2016).

A specific focus on mental health in high profile athletes may also have a transformative secondary benefit: increased help-seeking in the general population. Stigma related to mental health disorders is known to be a barrier for treatment, marked by fears around shame, embarrassment and negative social judgment (Clement et al., 2015). Young males in 
particular feel pressure from societal norms in regards to perceived masculine traits, which make psychological help-seeking a less favourable option (Seidler, Dawes, Rice, Oliffe, \& Dhillon, 2016; Vogel, Heimerdinger-Edwards, Hammer, \& Hubbard, 2011). This mindset is not unlike that for athletes generally (Doherty, Hannigan, \& Campbell, 2016), where a tendency to minimise showing weakness and vulnerability intrudes on help-seeking (Gulliver, Griffiths, \& Christensen, 2012).

Given that athletes are often idolised to represent influential role models without weaknesses or vulnerability, when they do disclose mental health problems, young people looking up to them may experience self-acceptance towards their own mental health concerns. Indeed, this is briefly addressed by Swann et al. (2018) who describe young male athletes being more engaged in mental health discussion when it comes from a sporting role model. This rationale underlies the recent 'Headcoach' initiative launched by headspace, Australia's National Youth Mental Health Foundation ${ }^{1}$. Headcoach profiles elite athletes from a range of sports in Australia discussing how they cope with mental health concerns such as anxiety, depression, stress and substance misuse, in addition to promoting general well-being. The Headcoach campaign emphasises that maintaining mental health is just as important as physical health and is primarily directed at improving engagement in young males. How this campaign may lead to an uptake in help-seeking and stigma reduction will be important to evaluate, and will guide policy and implementation to better engage young adults in early intervention.

This article is protected by copyright. All rights reserved. 
We propose that an enhanced focus on athlete mental health will have transformative outcomes over multiple at-risk populations. In agreement with the recent European Federation of Sport Psychology (Moesch et al., 2018) and International Society of Sport Psychology (Henriksen et al., 2019; Schinke et al., 2017) position statements, we echo the call for an increased focus on mental health education within sporting environments, from the elite level through to community participation at grass roots. There are also important opportunities for research and evaluation as new, sports-specific initiatives are developed. In addition, well-designed RCTs targeting common mental health disorders for athletes need to be conducted to better understand how to minimise athlete distress. It is likely that commonly used interventions seen in general clinical practice need to be adapted to be more sport-specific to achieve traction with athletes and coaches (Donohue et al., 2018; Moesch et al., 2018). Lastly, focusing on mental health in elite athlete populations may be an influential element of empowering those who may have previously been hesitant to seek help. We emphasise that future research findings around mental health in sport must be well communicated and translated to the community at large in order to have this effect. Publicly visible initiatives like Headcoach appear to be warranted, though work to examine the effect of such programs on mental health education and stigma-reduction would be beneficial.

\author{
Notes \\ ${ }^{1}$ Information about Headcoach can be accessed at https://headspace.org.au/headcoach/
}


Conflict of Interest: RP is the managing editor at Early Intervention for Psychiatry. She was not involved in any editorial decision making of this manuscript. CCW and SR have no conflicts to disclose.

\section{References}

Australia, S. (2018). Sport 2030 - National Sport Plan. Retrieved from https://www.sportaus.gov.au/nationalsportplan:

Baum, A. L. (2013). Suicide in athletes. Clinical sports psychiatry: An international perspective, 79-88.

Bauman, N. J. (2016). The stigma of mental health in athletes: are mental toughness and mental health seen as contradictory in elite sport? British Journal of Sports Medicine, 50(3), 135136. doi:10.1136/bjsports-2015-095570

Clement, S., Schauman, O., Graham, T., Maggioni, F., Evans-Lacko, S., Bezborodovs, N., . . . Thornicroft, G. (2015). What is the impact of mental health-related stigma on help-seeking? A systematic review of quantitative and qualitative studies. Psychological Medicine, 45(1), 11-27. doi:10.1017/S0033291714000129

Doherty, S., Hannigan, B., \& Campbell, M. J. (2016). The Experience of Depression during the Careers of Elite Male Athletes. Frontiers in Psychology, 7(1069). doi:10.3389/fpsyg.2016.01069

Donohue, B., Gavrilova, Y., Galante, M., Gavrilova, E., Loughran, T., Scott, J., . . Allen, D. N. (2018). Controlled Evaluation of an Optimization Approach to Mental Health and Sport Performance. Journal of Clinical Sport Psychology, 12(2), 234-267. doi:10.1123/jcsp.20170054

Gorczynski, P. F., Coyle, M., \& Gibson, K. (2017). Depressive symptoms in high-performance athletes and non-athletes: a comparative meta-analysis. British Journal of Sports Medicine, 51(18), 1348-1354. doi:10.1136/bjsports-2016-096455

Gouttebarge, V., Frings-Dresen, M. H., \& Sluiter, J. K. (2015). Mental and psychosocial health among current and former professional footballers. Occup Med (Lond), 65(3), 190-196. doi:10.1093/occmed/kqu202

Gulliver, A., Griffiths, K. M., \& Christensen, H. (2012). Barriers and facilitators to mental health helpseeking for young elite athletes: a qualitative study. BMC Psychiatry, 12(1), 157. doi:10.1186/1471-244x-12-157

Gulliver, A., Griffiths, K. M., Mackinnon, A., Batterham, P. J., \& Stanimirovic, R. (2015). The mental health of Australian elite athletes. Journal of Science and Medicine in Sport, 18(3), 255-261. doi:10.1016/j.jsams.2014.04.006

Henriksen, K., Schinke, R., Moesch, K., McCann, S., Parham, W. D., Larsen, C. H., \& Terry, P. (2019). Consensus statement on improving the mental health of high performance athletes. International Journal of Sport and Exercise Psychology, 1-8.

Hill, A., MacNamara, Á., \& Collins, D. (2015). Psychobehaviorally based features of effective talent development in Rugby Union: a coach's perspective. The Sport Psychologist, 29(3), 201-212.

This article is protected by copyright. All rights reserved. 
Hill, A., MacNamara, Á., Collins, D., \& Rodgers, S. (2016). Examining the Role of Mental Health and Clinical Issues within Talent Development. Frontiers in Psychology, 6(2042). doi:10.3389/fpsyg.2015.02042

Hughes, L., \& Leavey, G. (2012). Setting the bar: athletes and vulnerability to mental illness. British Journal of Psychiatry, 200(2), 95-96. doi:10.1192/bjp.bp.111.095976

Kessler, R. C., Angermeyer, M., Anthony, J. C., De Graaf, R., Demyttenaere, K., Gasquet, I., . . Haro, J. M. (2007). Lifetime prevalence and age-of-onset distributions of mental disorders in the World Health Organization's World Mental Health Survey Initiative. World psychiatry, 6(3), 168.

Liddle, S. K., Deane, F. P., \& Vella, S. A. (2017). Addressing mental health through sport: a review of sporting organizations' websites. Early Intervention in Psychiatry, 11(2), 93-103. doi:doi:10.1111/eip.12337

Moesch, K., Kenttä, G., Kleinert, J., Quignon-Fleuret, C., Cecil, S., \& Bertollo, M. (2018). FEPSAC position statement: Mental health disorders in elite athletes and models of service provision. Psychology of Sport and Exercise, 38, 61-71. doi:https://doi.org/10.1016/i.psychsport.2018.05.013

Rice, S. M., Parker, A. G., Rosenbaum, S., Bailey, A., Mawren, D., \& Purcell, R. (2018). Sport-Related Concussion and Mental Health Outcomes in Elite Athletes: A Systematic Review. Sports Medicine, 48(2), 447-465. doi:10.1007/s40279-017-0810-3

Rice, S. M., Purcell, R., De Silva, S., Mawren, D., McGorry, P. D., \& Parker, A. G. (2016). The Mental Health of Elite Athletes: A Narrative Systematic Review. Sports Med, 46(9), 1333-1353. doi:10.1007/s40279-016-0492-2

Schinke, R. J., Stambulova, N. B., Si, G., \& Moore, Z. (2017). International society of sport psychology position stand: Athletes' mental health, performance, and development. International Journal of Sport and Exercise Psychology, 1-18. doi:10.1080/1612197X.2017.1295557

Seidler, Z. E., Dawes, A. J., Rice, S. M., Oliffe, J. L., \& Dhillon, H. M. (2016). The role of masculinity in men's help-seeking for depression: A systematic review. Clinical Psychology Review, 49, 106118. doi:https://doi.org/10.1016/i.cpr.2016.09.002

Swann, C., Telenta, J., Draper, G., Liddle, S., Fogarty, A., Hurley, D., \& Vella, S. (2018). Youth sport as a context for supporting mental health: Adolescent male perspectives. Psychology of Sport and Exercise, 35, 55-64. doi:https://doi.org/10.1016/j.psychsport.2017.11.008

Vogel, D. L., Heimerdinger-Edwards, S. R., Hammer, J. H., \& Hubbard, A. (2011). "Boys don't cry": Examination of the links between endorsement of masculine norms, self-stigma, and helpseeking attitudes for men from diverse backgrounds. Journal of Counseling Psychology, 58(3), 368-382. doi:10.1037/a0023688 


\section{University Library}

\section{- M M N E R VA A gateway to Melbourne's research publications}

Minerva Access is the Institutional Repository of The University of Melbourne

Author/s:

Walton, CC;Purcell, R;Rice, S

Title:

Addressing mental health in elite athletes as a vehicle for early detection and intervention in the general community

Date:

2019-07-02

Citation:

Walton, C. C., Purcell, R. \& Rice, S. (2019). Addressing mental health in elite athletes as a vehicle for early detection and intervention in the general community. EARLY INTERVENTION IN PSYCHIATRY, 13 (6), pp.1530-1532. https://doi.org/10.1111/eip.12857.

Persistent Link:

http://hdl.handle.net/11343/286108 